\title{
MOVIMENTO AFROVEGANO E INTERSECCIONALIDADE: DIÁLOGOS POSSÍVEIS ENTRE O MOVIMENTO ANIMALISTA E O MOVIMENTO NEGRO
}

\author{
AFROVEGAN MOVEMENT AND INTERSECTIONALITY: POSSIBLE DIALOGUES \\ BETWEEN ANIMALIST MOVEMENT AND BLACK MOVEMENT
}

Recebido:23.09.2019

Aprovado: 30.01 .2020

\author{
Nina Trícia Disconzi \\ Doutora em Direito do Estado pela Universidade de \\ São Paulo. Professora da Universidade Federal de \\ Santa Maria (UFSM). Coordenadora do Grupo de \\ Pesquisa, cadastrado no CNPQ (Grupo de Pesquisa \\ em Direito dos Animais, denominado GPDA), da \\ Universidade Federal de Santa Maria (UFSM). \\ EMAIL: ninadisconzi@uol.com.br \\ LATTES: http://lattes.cnpq.br/7964995474008653 \\ ORCID: http://orcid.org/0000-0002-9625-7147
}

\author{
Fernanda dos Santos Rodrigues Silva \\ Mestranda em Direito pelo Programa de Pós- \\ Graduação em Direito da Universidade Federal de \\ Santa Maria (UFSM). Advogada. \\ EMAIL: fernanda_1849@hotmail.com \\ LATTES: http:/ /lattes.cnpq.br/8893649892589552 \\ ORCID: http:/ / orcid.org/0000-0002-5549-0217
}

RESUMO: O presente artigo tem por finalidade a proposição da utilização do conceito de interseccionalidade, cunhado por Kimberle Crenshaw, para possibilitar um diálogo entre as causas animal e antirracista para além da comparação de opressões. Com efeito, sugere-se, a partir da identificação de pontos em comum de ambas as lutas (e não das opressões) e da base do Movimento Afrovegano, uma forma de cooperação que leve a uma emancipação em conjunto, com vistas à superação do paradigma jurídico racional dominante e sem que uma demanda se sobreponha à outra. Para tanto, utilizou-se como método de abordagem o dedutivo e, como métodos de procedimento, o histórico e o tipológico. Por fim, a técnica de pesquisa empregada foi a bibliográfica.

PALAVRAS-CHAVE: interseccionalidade. Movimento animalista. Movimento negro.

\begin{abstract}
The purpose of this article is to propose the use of the concept of intersectionality, coined by Kimberle Crenshaw, to enable a dialogue between animal and antiracist causes in addition to comparing oppressions. In fact, it is suggested, from the identification of common points of racial and animal oppression e from the afrovegan movement, a form of cooperation of the social struggles leading to a joint emancipation, with a view to overcoming the dominant rational legal paradigm and without a demand overlap the other. In this case, it was used the dialectical approach method and, as methods of procedure, the historical and the typological. Finally, the research technique employed was the bibliographical.
\end{abstract}

KEYWORDS: intersectionality. Animalist movement. Black movement.

SUMÁRIO: 1 Introdução 2 Opressão racial x opressão animal: uma histórica comparação 3 A necessidade de superação do paradigma jurídico racional: um horizonte em comum 3.1 A 
objetificação da população negra 3.2 A objetificação de animais não-humanos 4 Movimento afrovegano: a interseccionalidade como conceito essencial para a articulação entre o movimento negro e o movimento animalista 5 Conclusão 6 Notas de referência

\section{Introdução}

Apesar de eventualmente destoarem sobre a minoria a que pretendem proteção, as lutas sociais são historicamente conhecidas por buscarem enfrentar desigualdades e injustiças contra determinados grupos que compõem a sociedade e que, historicamente, por uma razão ou outra, são marginalizados por uma ideologia dominante. Em razão disso, em alguns momentos, as suas pautas podem ser abordadas de maneira conjunta, a fim de somar esforços para a superação de mais de uma forma de opressão.

No caso, uma temida comparação ${ }^{1}$ entre duas lutas contra hegemônicas, especificamente, tem chamado a atenção desde longa data, em razão de um aparente conflito nas suas pautas, a saber, a luta antirracista e a luta animalista. Por um lado, a histórica resistência da população negra contra discursos racistas institucionalizados e velados dentro da sociedade e, do outro, a luta de ativistas em prol, principalmente, do reconhecimento de animais nãohumanos como sujeitos de direito.

Superficialmente, uma comparação rasa entre racismo e especismo e entre a escravidão humana e a escravidão animal tem suscitado intensos desconfortos, em especial, dentro do movimento negro, que não vê com bons olhos esta forma de abordagem. E, também, não haveria de ser de outra forma, uma vez que um dos pilares da escravização da população negra foi a constante desumanização do grupo, com sua comparação a animais não-humanos como uma maneira de inferiorizá-la.

Contudo, é sabido que ambas as causas, cada uma a sua maneira, lutam contra um status quo que é voltado para a marginalização, exclusão e objetificação das minorias vulneráveis de que são aliadas. Em razão disso, questiona-se: em que medida as lutas animalista e antirracista podem contribuir uma para a outra, para além de uma mera comparação entre opressões?

Para responder a esta indagação, o presente trabalho utilizou-se do método de abordagem dedutivo, buscando, primeiramente, apresentar as aproximações recorrentes entre as duas formas de opressão, ou seja, o que se tem construído entre analogias e comparações. $\mathrm{Na}$ sequência, busca-se destacar a importância da luta contra o paradigma jurídico racional tanto pela causa antirracista como pela causa animal, de modo a delimitar uma pauta em comum entre ambas. Nesse sentido, com vistas à superação de uma visão dicotômica entre as duas pautas, o que se propõe é a adoção do conceito de interseccionalidade, de Kimberle Crenshaw, bem como as bases do Movimento Afrovegano, para compreender de que maneira as lutas animalista e antirracista podem colaborar uma para outra, para além da comparação de opressões.

Como método de procedimento, optou-se pelo método tipológico, ao se propor modos ideais de intersecção entre a causa animal e a causa antirracista, com a finalidade de comungar esforços contra um possível "inimigo" em comum, mas sempre observando a necessidade de uma luta não se sobrepor à outra. Por fim, a técnica de pesquisa bibliográfica foi a principal ferramenta para a construção do trabalho.

\section{Opressão Racial X Opressão Animal: Uma Histórica Comparação}

Não é de hoje que se busca uma aproximação entre as opressões racial e animal, contudo, nem sempre pessoas negras e animais não-humanos foram utilizados no mesmo 
contexto com uma finalidade positiva. O processo de discriminação racial utilizou-se, desde o princípio, da comparação de negros e negras com animais não-humanos como algo pejorativo, como uma forma de inferiorizar ainda mais o primeiro grupo e de privá-lo de condições básicas de vida.

Com efeito, ainda que não houvesse um acordo expresso, tacitamente havia se reconhecido que a desumanização, isto é, o "rebaixamento" das pessoas negras à mesma categoria de animais não-humanos representava uma ofensa. Em verdade, isso significava, inclusive, que o tratamento totalmente inaceitável quando dispensado para seres humanos era, na verdade, a maneira adequada de se lidar com animais não-humanos. ${ }^{2}$

Nesse sentido, a partir de um processo de objetificação, a população de escravos e escravas era tratada como mercadoria pelos senhores de engenho, isto é, como sua propriedade, ${ }^{3}$ e não como seres humanos que haviam sido escravizados e que estavam em uma situação degradante. Um exemplo notório dessa forma de pensar é que, após o término do tráfico de escravos nos Estados Unidos da América, um tribunal da Carolina do Sul decidiu que, tais como outros animais, as escravas não tinham nenhum direito sobre seus filhos e filhas, razão pela qual estes poderiam ser vendidos em qualquer idade. ${ }^{4}$

Até hoje, inclusive, ainda é comum a recorrência de casos de injúria racial em que a principal ofensa feita à vítima é a sua comparação a algum animal não-humano como uma forma de depreciá-la. No Rio Grande do Sul, em 2014, por exemplo, uma torcedora do time de futebol Grêmio e outras três pessoas foram indiciadas pelo crime após gritar para o goleiro negro do time adversário, durante a partida, a palavra "macaco" diversas vezes. ${ }^{5}$

Em razão disso, qualquer forma de aproximação entre as opressões racial e animal não pode ser feita de maneira superficial. Mesmo nos casos em que a analogia se justifica, é preciso cuidado, especialmente, para que não ocorra a utilização da luta antirracista somente como forma de sensibilizar o público para a causa animal. De fato,

Apesar da estrutura de opressão de animais e pessoas negras serem
similares, comparar constantemente a opressão dos animais com a
escravidão ou linchamento de pessoas negras parece sugerir que a única
maneira na qual o racismo cabe na discussão é por sua utilidade em produzir
analogias para beneficiar apenas os animais. (tradução nossa). ${ }^{6}$

Em 2007, por exemplo, o site Afropress fez uma nota sobre a representação feita, à época, pela ONG ABC sem Racismo ao Ministério Público, requerendo a investigação da prática de crime de apologia ao racismo na "associação de imagens feita por um grupo de defesa animal, auto-denominado vegan (ou vegano), que associa a imagem da escrava Anastácia (..) a cães com focinheira" ${ }^{7}$. Na ocasião, a página referiu respeitar "a filosofia das pessoas que, por princípio, acreditam que não deve haver distinção entre animais não dotados de razão e seres humanos, que tem esse atributo", mas que o que não era aceitável era "a tentativa deste ou de qualquer outro grupo, de pretender dizer o que deve ou não afetar nossa sensibilidade, como negros $(. . .)^{\prime \prime}$.

No ponto, em que pese não seja o objetivo do presente trabalho repetir discursos que, de forma crítica e justificada, demonstram os pontos de convergência entre as opressões racial e animal, é importante referir, ainda que de forma breve, os seus principais pontos, a começar pela abordagem clássica de equivalência entre racismo e especismo. Com seu maior expoente na figura do pesquisador Richard Ryder, o conceito deste último pode ser definido como "a discriminação sistemática ou o tratamento diferenciado justificado pela pertença a uma espécie (biológica), quando a espécie não é, em si mesma, um critério moralmente relevante" ${ }^{\prime 9}$.

Nesse sentido, o especista seria aquele que deduz "o status moral de uma criatura a partir de uma avaliação moral com parcialidade tendenciosa, em favor dos interesses próprios do

92 | Revista Brasileira de Direito Animal, e-issn: 2317-4552, Salvador, volume 15, n. 01, p.90-108, Jan-Abril 2020 
Homo sapiens, sobre um fundamento não suficientemente justificado, ou seja, tautológico, arbitrário ou irrelevante" ${ }^{10}$. Segundo essa linha argumentativa, recorrente dentro dos estudos da Ética Animal, a alegação é a seguinte:

(i) O racismo é errado, os racistas são imorais e as atitudes racistas são injustas. (ii) Ora, o especismo é análogo ao racismo: ambos tratam de modo moralmente diferente indivíduos que são semelhantes nos aspectos moralmente relevantes - baseados (no primeiro caso) na espécie biológica da criatura e (no segundo) na raça da pessoa. (iii) Logo, o especismo também é moralmente condenável. ${ }^{11}$

Em outras palavras, numa perspectiva lógica, seria possível dizer que racismo e especismo são formas de opressão análogas - não iguais. Com efeito, nas palavras de Peter Singer, "deveria ser óbvio que as objeções fundamentais ao racismo e ao sexismo (...) aplicam-se igualmente ao especismo"12, já que

(...) é com base nesse princípio [da igualdade] que a atitude que podemos chamar de "especismo", por analogia ao racismo, também deve ser condenada.

(...) Os racistas violam o princípio da igualdade ao conferirem mais peso aos interesses de membros de sua própria raça quando há um conflito entre seus interesses e os daqueles que pertencem a outras raças. (...) Analogamente, os especistas permitem que os interesses de sua própria espécie se sobreponham àqueles maiores de membros de outras espécies. ${ }^{13}$

Veja-se que, para o autor, "o padrão é idêntico em todos os casos"14, com uma evidente violação ao princípio da igualdade. Dessa forma, não haveria que se falar em luta antirracista sem que isso implique necessariamente em uma luta antiespecista. Nas palavras de Richard Ryder, novamente, especismo é como racismo ou sexismo: um preconceito baseado em diferenças físicas irrelevantes moralmente. ${ }^{15}$

Tanto é por isso que, conforme referido anteriormente, uma das bases da discriminação racial é a comparação de pessoas negras com animais não-humanos. Ambos são considerados como seres inferiores que, por predisposições naturais, possuiriam capacidade de raciocínio reduzido $^{16}$ ou, no caso de homens e mulheres negras, em específico, estariam em grau mais atrasado de desenvolvimento humano, razão pela qual caberia a civilizações mais evoluídas, como a europeia, a missão de conduzi-los. ${ }^{17}$

Para Tom Regan, por sua vez, como seria possível "acreditar que ser membro de uma espécie marque um limite defensável entre os animais que têm e os que não têm direitos?"18. Com efeito, isso constituiria um "preconceito do mesmo tipo que o racismo e o sexismo, o preconceito conhecido como especismo" ${ }^{19}$. Gary Francione, por fim, refere que o especismo e a escravidão humana são similares na medida em que animais não-humanos e humanos escravizados têm um interesse básico em não serem tratados como coisas e, ainda assim, são tratados como tais baseado em critérios moralmente irrelevantes. ${ }^{20}$

Assim, não é possível deixar de considerar que as lutas animalista e antirracista poderiam vir a contribuir uma para a outra - a crítica que se faz, porém, a uma analogia das formas de opressão é, de acordo com o já referido por Carlos Naconecy, que "enfatizar de modo ligeiro e de forma crua as semelhanças morais entre racismo e especismo" ${ }^{21}$ pode resultar em um paralelismo rigoroso ou completo entre ambos, o que seria enganador. ${ }^{22}$

Como bem aduz Marjorie Spiegel, ao escolher o título de seu livro elucidativo sobre o tema, trata-se de uma temida comparação, pois toca em zonas extremamente sensíveis para os

93 | Revista Brasileira de Direito Animal, e-issn: 2317-4552, Salvador, volume 15, n. 01, p.90-41, Jan-Abril 2020 
dois lados. No ponto, o próprio termo "comparação" acaba por permitir uma compreensão inicial de antagonismo, já que um dos significados da palavra é justamente "pôr-se em confronto" 23 .

Nessa senda, em que pese a compreensão da analogia entre racismo e especismo permitir entender de que maneira tanto pessoas negras, como animais não-humanos são tratados a partir de uma perspectiva que os objetifica e permite a perpetuação da sua discriminação, somente isso não garante a compreensão do porquê, por exemplo, houve um embate ferrenho entre a luta antirracista e a animalista por ocasião do julgamento do Recurso Extraordinário no 494601/RS. ${ }^{24}$

Na ocasião, o Supremo Tribunal Federal teve de decidir a respeito da constitucionalidade de uma lei gaúcha que permitiu a realização do sacrifício de animais em rituais de religião de matriz africana, deixando de configurar tal ato como maus-tratos. Com efeito, a controvérsia foi a respeito do parágrafo único incluído no art. 2o do Código Estadual de Proteção aos Animais (Lei estadual no 11.915/2003, do Rio Grande do Sul), ${ }^{25}$ que assim passou a constar:

Art. 2o - É vedado:

I - ofender ou agredir fisicamente os animais, sujeitando-os a qualquer tipo de experiência capaz de causar sofrimento ou dano, bem como as que criem condições inaceitáveis de existência;

II - manter animais em local completamente desprovido de asseio ou que Ihes impeçam a movimentação, o descanso ou os privem de ar e luminosidade;

III - obrigar animais a trabalhos exorbitantes ou que ultrapassem sua força;

IV - não dar morte rápida e indolor a todo animal cujo extermínio seja necessário para

consumo;

$\checkmark$ - exercer a venda ambulante de animais para menores desacompanhados por responsável legal;

$\mathrm{VI}$ - enclausurar animais com outros que os molestem ou aterrorizem;

VII - sacrificar animais com venenos ou outros métodos não preconizados pela Organização Mundial da Saúde - OMS -, nos programas de profilaxia da raiva.

Parágrafo único - Não se enquadra nessa vedação o livre exercício de cultos e liturgias das religiões de matriz africana. (grifo nosso).

A partir da nova redação, portanto, excluiu-se expressamente do rol que vedava os maus-tratos aos animais não-humanos a utilização destes seres em cultos de religiões de matriz africana. No ponto, desde o início, é importante destacar que a Lei fez menção exclusivamente a uma única religião, o que permitiria inferir, em um primeiro momento, que apenas as religiões de matriz africana realizariam rituais com animais não-humanos e, portanto, precisariam dessa excludente.

Isso leva ao questionamento, por sua vez, do que é concebido como sacrifício para ritual religioso. É necessário que os próprios devotos realizem o sacrifício? A mera presença de animais não-humanos mortos em alguma cerimônia é suficiente, independentemente se o abate foi industrializado e, destarte, terceirizado? De fato, o debate não pode ser feito sem compreender, pelo menos, o porquê somente as religiões de matriz africana tiveram de ser expressamente referidas na Lei.

Acaso observada a situação da religião católica, por exemplo, verifica-se que na chamada Sexta-Feira Santa, data em que teria ocorrido a morte de Jesus Cristo, os devotos devem evitar, em regra, o consumo de carne vermelha e de frango, como forma de respeito ao sacrifício do 
próprio messias. ${ }^{26}$ Em razão disso, é frequente o consumo da carne de peixe nessa ocasião, o que seria uma forma de substituição à carne que não pode ser consumida. ${ }^{27}$

No islamismo e no judaísmo, por sua vez, animais também são sacrificados para rituais específicos, "em que vacas, cabras, ovelhas ou aves de curral devem ser sacrificadas com um corte na garganta e deixadas dessangrando por horas até morrer" ${ }^{\prime 2}$. No Brasil, para a produção dessa carne, chamada de halal, "há centenas de funcionários de países árabes trabalhando em grandes frigoríficos para garantir que o abate siga as regras que permitem que o produto seja qualificado como halal”29, uma vez que os países importadores fiscalizam em conjunto.

Por que razão, porém, não foi feita menção a estas religiões quando da edição da Lei? Com efeito, não há que se falar em falta de interesse. A comunidade judaica no Brasil alcança em torno de 120 mil cidadãos, ${ }^{30}$ enquanto que católicos constituem $64,6 \%$ da população, ambas as informações segundo dados do último Censo do IBGE. ${ }^{31}$ Destarte, tais religiões também deveriam ostentar de proteção estatal para que suas práticas não fossem enquadradas como maus-tratos aos animais não-humanos.

A construção até aqui permite compreender que, de fato, independentemente da religião acima referida, há uma instrumentalização dos animais não-humanos para finalidades específicas dentro dos cultos. Tal objetificação, como bem referido, assemelha-se à objetificação, com os devidos recortes, que pessoas negras sofrem cotidianamente desde o período da escravidão no país. Contudo, somente a analogia de opressões não permite compreender o porquê o resultado da decisão proferida pelo Supremo Tribunal Federal foi tão ferrenhamente defendido pelo movimento negro.

No ponto, a tese da Suprema Corte restou assim definida: "é constitucional a lei de proteção animal que, a fim de resguardar a liberdade religiosa, permite o sacrifício ritual de animais em cultos de religiões de matriz africana". ${ }^{32}$ Somente o paralelismo entre as formas de opressão, porém, não permite identificar questões consideradas secundárias ao tema, mas que são seus reflexos imediatos. No ponto, não se relembra em primeiro plano, de que o histórico escravocrata do país já garante a criminalização diária das religiões de matriz africana.

No período colonial, as práticas advindas dessas religiões "eram consideradas manifestações de magia ou feitiçaria, e passíveis de punição pelo código canônico e perseguidas pela igreja e pelas autoridades" ${ }^{\prime 33}$. Atualmente, entre 2015 e 2017, a cada 15 horas um relato por motivo de intolerância religiosa foi relatado no Brasil, sendo que a Secretaria de Direitos Humanos do Rio de Janeiro, especificamente, apurou que, entre agosto e outubro de 2017, 91\% das denúncias de preconceito religioso eram contra credos de matriz africana. ${ }^{34}$

Destarte, em que pese a Lei questionada em sede de Recurso Extraordinário já permitisse o sacrifício animal em religiões de matriz africana, estas sofrem historicamente com o preconceito tanto religioso como racial, que criminaliza as suas práticas no dia a dia sem que seja necessária uma legislação penal para tanto. Uma decisão do Supremo Tribunal Federal, portanto, que viesse a legalizar, no sentido literal, a condenação das práticas realizadas nos terreiros poderia prejudicar sobremaneira a situação dessas religiões no Brasil.

Veja-se que, em nenhum momento, sustenta-se que a pauta deva se encerrar por aqui. Como bem aduz Nataly Neri, ${ }^{35}$ o que se pontua é a necessidade de se considerar os possíveis resultados futuros de uma decisão contrária à que foi manifestada pela luta antirracista. Por outro lado, isso também não significa que não há uma forma de ambas as causas atuarem em conjunto.

Antes, porém, de buscar o embate em situações que podem, eventualmente, resultar em danos incalculáveis sobre uma ou outra, o que se propõe é uma perspectiva em que ambas sejam contempladas, buscando a superação não somente da mera comparação de opressões, mas de uma barreira em comum entre ambas. 


\section{A Necessidade De Superação Do Paradigma Jurídico Racional: Um Horizonte Em Comum}

Antes de se trabalhar sobre a forma que se pretende sugerir de atuação em conjunto das causas animal e racial, é preciso definir que barreira em comum é essa que se está a ponderar. Por óbvio, aqui não se exclui o fato de que não é possível afirmar a existência de somente um obstáculo em comum entre os movimentos, contudo, para fins deste trabalho, o recorte escolhido foi o do paradigma jurídico racional e dominante.

Com efeito, desde Bacon e Descartes, o pensamento científico teve uma guinada, de forma a alocar o racionalismo como a principal ferramenta para explicar o mundo. Um dos principais suportes da modernidade, apesar das críticas que vieram na sequência, foi justamente o pensamento cartesiano, segundo o qual "é quase impossível que nossos juízos sejam tão puros ou tão firmes como seriam se pudéssemos utilizar totalmente a nossa razão desde o nascimento e se não tivéssemos sido guiados senão por ela" ${ }^{36}$.

Veja-se que a razão desponta como o filtro mais desejado para se enxergar a realidade é através dela que se tornam possíveis juízos mais objetivos e, supostamente, imparciais. Para tanto, é necessário que haja uma separação explícita entre sujeito e objeto que permita o verdadeiro conhecimento, o que significa, em outras palavras

(1) que a razão só pode lidar com o que se manifesta conforme suas exigências, sendo inadequado pretender considerar algo independentemente dessa manifestação;

(2) que, para serem conhecidos, os objetos devem deixar-se "ver" completamente por ela, apesar da resistência que possam apresentar. ${ }^{37}$

Nas ciências jurídicas, essa lógica cartesiana "conduziu à observância, cada vez mais fervorosa, de um dogma cristalizado na atuação dos operadores do Direito: a segurança jurídica" ${ }^{\prime 3}$. Nesse sentido, passou-se não somente a almejar a separação do julgador e sua subjetividade, devendo o primeiro se limitar a traduzir a vontade da lei no caso concreto, como também foi introduzido no âmbito do processo a ideia de que o seu objetivo é alcançar a verdade real. $^{39}$

Para Segato, porém, essa separação entre objeto e sujeito ultrapassa a simples dualidade, gerando, na verdade, uma lógica binária. Nas palavras da autora,

Enquanto na dualidade a relação é de complementaridade, a relação binária é suplementar, um termo suplementa o outro, e não o complementa. Quando um desses termos se torna "universal", quer dizer, de representatividade geral, o que era hierarquia se transforma em abismo, e o segundo termo se converte em resto e resíduo: essa é a estrutura binária, diferente da dual. ${ }^{40}$

Em razão disso, os pilares do cientificismo moderno acabam por permitir a construção de uma relação que resulta na objetificação daqueles que são colocados no lugar do outro - seja um conhecimento a ser esmiuçado, seja um povo que é colocado na situação de diferente do que foi considerado universal até então.

Essa objetificação, porém, aplicava-se tanto a povos que não se encaixavam nesse padrão, como a animais não-humanos. Para Descartes, havia uma diferenciação notória entre animais humanos e não-humanos, já que os primeiros eram os únicos capazes de exercer seu juízo racional. Conforme o autor, animais não-humanos poderiam ser comparados, inclusive, a 
máquinas, se estas "fossem providas de órgãos e do aspecto de um macaco, ou de qualquer outro animal irracional" ${ }^{41}$.

Esse paradigma, porém, não se instalou somente no campo da filosofia. As ciências jurídicas, isto é, as teorias que tentaram abordar o Direito da mesma forma com que se abordavam as ciências exatas, por meio do raciocínio lógico, fez com que raízes racionalistas ganhassem espaço também nesse terreno.

Kant, Kelsen e, mais recentemente, Karl Popper, foram alguns dos pensadores mais notórios a reforçar o paradigma jurídico racional e dominante. Para o segundo, por exemplo, há uma clara distinção entre a função da ciência jurídica e a função da autoridade jurídica - ao passo que as proposições normativas formuladas pela primeira, "que descrevem o Direito e que não atribuem a ninguém quaisquer deveres ou direitos" ${ }^{\prime 2}$, podem ser verídicas ou inverídicas, as normas estabelecidas pela segunda, "que atribuem deveres e direitos aos sujeitos jurídicos"43, somente podem ser válidas ou inválidas.

Esse entendimento de Kelsen é no mesmo sentido de Popper, para quem "nunca podemos provar uma teoria, para corroborá-la; o que podemos é pô-la a prova, em situações cruciais, para ver se ela resiste ${ }^{\prime 4}$. Em razão disso, há certa exclusão da experiencia como um aspecto relevante, para fins de demarcar o que é científico.

Todo esse processo, ao final, leva à uma separação irremediável entre sujeito e objeto, que precisam estar em lugares diferentes para que o processo científico não seja maculado por subjetividades. No momento que o local do sujeito, porém, é absorvido por um padrão, permitese a exclusão do que é diferente, que é alocado na condição de objeto.

\subsection{A Objetificação Da População Negra}

No que tange às consequências para a população, a objetificação deste povo, que não se encaixava nos moldes europeus e, portanto, constituía o Outro, o objeto, permitiu que negros e negras fossem comercializados em diversos países como mercadoria e mão-de-obra barata, processo este intensificado no período pós-século XV.

As teorias científicas que embasaram essa forma de exploração, por sua vez, voltada especificamente para a subjugação de populações negras, foram as chamadas teorias raciais, que apontavam uma suposta inferioridade desse grupo ao proclamar que, em uma imaginária escala de evolução da civilização, ele se encontrava na base, enquanto que países europeus assumiam seu topo. ${ }^{45}$ Em razão disso, aspectos de países da Europa, desde religião até formas de se vestir, eram considerados um degrau mais avançado do desenvolvimento humano, o que, como tal, autorizá-los-ia à condução dos povos "inferiores" na direção da civilização.

No ponto, uma das razões para determinar a sua inferioridade é que, para os religiosos brancos puritanos e colonizadores, "progresso" e "civilização" eram termos medidos, dentre outras formas, a partir da distância com que as pessoas conseguiam distanciar elas mesmas da Natureza. ${ }^{46}$ Assim, as religiões de matriz africana representavam um atraso a ser superado, uma vez que possuíam (e ainda possuem) o meio ambiente como elemento essencial de comunicação com o sagrado, em que os vários deuses (orixás) caracterizavam um elemento constituidor do universo. ${ }^{47}$

É nesse contexto que a desvalorização da história e cultura negras passam a constituir também um dos pilares da escravização. Ignora-se todo o tipo de contribuição e produção de conhecimento do povo africano sob a falsa justificativa de que esta não seria uma contribuição válida. Para além da escravização de corpos negros, portanto, com a sua utilização para a 
exploração na agricultura, a subjugação dessa população utilizou-se também de diversas formas de supressão da sua existência cultural e socialmente.

Ainda, é justamente a partir do epistemicídio dos saberes produzidos por pessoas negras é que foi possível, igualmente, realizar o processo de desumanização completa desses corpos. Com efeito, em que pese formulado inicialmente por Boaventura de Souza Santos, Sueli Carneiro destaca que o termo representa, "para além da anulação e desqualificação do conhecimento dos povos subjugados, um processo persistente de produção da indigência cultural: pela negação ao acesso à educação, sobretudo de qualidade; [e] pela produção da inferiorização intelectual (...)" ${ }^{48}$, por exemplo.

Nesse sentido, com a inferiorização de qualquer aspecto cultural de uma comunidade, retira-se também um elemento importante na constituição de sua humanidade, permitindo-se, assim, que a comparação de seus membros com animais sirva como uma forma de ratificar o seu desvalor. No ponto, o papel do Direito nessa trajetória escravocrata era o de manter o status quo da classe dominante, assegurando legalmente o tratamento destinado a homens e mulheres negros e negras.

$\mathrm{Na}$ escravidão, o direito colonial português era o que servia para esse fim, em que "o escravo era considerado um bem semovente, definido em termos jurídicos como uma coisa, privado de direitos, impedido de possuir propriedade e incapaz de manter qualquer obrigação" ${ }^{\prime 9}$. Após a abolição, em que pese a ausência de normas jurídicas que determinassem a superioridade de pessoas brancas na sociedade, a política criminal do incipiente período republicano passou a adotar medidas que criminalizavam diretamente os ex-escravos, como a proibição de exercícios de agilidade e destreza corporal conhecidos como "capoeiragem" em ruas e praças públicas. ${ }^{50}$

Até hoje, os dados INFOPEN - Mulheres de $2018^{51}$ comprovam que essa minoria continua sendo o alvo do sistema criminal do Estado, uma vez que, considerando o aumento do encarceramento de mulheres no Brasil, 62\% deste público é composto por mulheres negras de 18 a 24 anos, que se encontram presas em razão de crimes que envolvem seus familiares ou companheiros. Os homens negros, por sua vez, não ficam muito atrás, tendo em vista que constituem também a maior parte dos encarcerados dos presídios masculinos e são os maiores alvos da violência policial. ${ }^{52}$

O principal empecilho para se escancarar essa objetificação que é fomentada pelo próprio Direito estatal está, hoje em dia, justamente no fato de que a lei não traz qualquer norma direta de discriminação racial. É o contexto sociocultural e histórico do país que permite demonstrar que a aparente racionalidade jurídica, em que "todos são iguais perante a lei", na verdade, resta eivada de um caráter preconceituoso e seletivo.

\subsection{A Objetificação De Animais Não-Humanos}

Em que pese de uma maneira totalmente distinta, o mesmo paradigma jurídico racional e dominante que permitiu (e ainda permite) a objetificação de pessoas, operou também para a subjugação e domínio dos animais não-humanos. Com efeito, como bem referido anteriormente, a superioridade racional dos animais humanos é reconhecida como a justificativa para a subjugação das demais espécies de animais.

Na verdade, de forma breve, é possível elencar três pilares que garantem a manutenção da opressão sobre animais não-humanos, conceituados por Carol Adams, em seu livro "A política sexual da carne" ${ }^{\prime 53}$. O primeiro é o "referente ausente", que, nas palavras da autora, seria "o que separa o carnívoro do animal e o animal do produto final", mantendo "a nossa 'carne' separada de qualquer ideia de que ela ou ele já foi um animal". 
O segundo pilar é o do "retalhamento", que determina a fragmentação daquele ser vivo em diversas partes, a fim de que não seja mais possível a sua identificação e, assim, permita aos consumidores, desvincular o que lhes é servido do animal vivo que foi morto para sua utilização. Nesse sentido, a tríade é concluída pelo "pensamento literal e pensamento simbólico", em que este último é justamente o resultado da abstração sobre o que se está comendo. Apesar de saber que aquele "coração" e aquele "pedaço de peito de frango" são, efetivamente, de um frango, o pensamento simbólico permite abstrair esses termos do animal que foi, de fato, separado, morto, fatiado e embalado para ser servido à mesa.

Assim, reforça-se a objetificação substancial dos animais não-humanos que, mesmo diante do reconhecimento de sua senciência, ainda são submetidos a determinados procedimentos, mediante o que se chama de "sofrimento necessário". No ponto, a Declaração de Cambridge sobre a Consciência, em 2012, foi um marco para o direito dos animais, na medida em que afirmou a existência de "evidências convergentes [que] indicam que os animais não humanos têm os substratos neuroanatômicos, neuroquímicos e neurofisiológicos de estados de consciência juntamente como a capacidade de exibir comportamentos intencionais" ${ }^{\prime \prime 4}$.

É por essa razão que a luta animalista, em verdade, é uma luta contra qualquer forma de sofrimento animal - independentemente se é para o abate para consumo ou para alguma forma de sacrifício, qualquer que seja a religião. Isso porque, em qualquer situação, já restou comprovado que o animal sofrerá, pois é capaz de sentir dor.

Nesse sentido, o art. 225, da Constituição Federal já vedava, em seu inciso VII quaisquer práticas "que coloquem em risco sua função ecológica, provoquem a extinção de espécies ou submetam os animais a crueldade" ${ }^{55}$. Assim, "a senciência animal é juridicamente valorada (...), pela positivação da regra fundamental do Direito Animal contemporâneo: a proibição das práticas que submetam os animais à crueldade" ${ }^{\prime 56}$.

Por fim, não se pode deixar de mencionar que "o consumo de carne é um constructo, uma força, uma realidade econômica" ${ }^{57}$, isto é, está diretamente ligada à economia de capital mundialmente difundida. Consumir carne é, também, gerar lucro para a indústria alimentícia. Sua produção, nesse sentido, não é mero aspecto estrutural, mas, também, provida pelo sistema capitalista atualmente vigente em boa parte dos países pelo mundo.

\section{Movimento Afrovegano: A Interseccionalidade Como Conceito Essencial Para a Articulação Entre o Movimento Negro e o Movimento Animalista}

Uma vez demonstrado que o paradigma jurídico racional é uma barreira em comum entre os movimentos negro e animalista, faz-se necessário pensar maneiras de superação em conjunto dessa pauta por ambas as partes. No ponto, já se sabe que as formas de opressão racial e animal se aproximam e que existe uma analogia entre as duas, entretanto, entende-se que, com vistas a complementar essa compreensão, o conceito de interseccionalidade possui importância fundamental.

Conforme a definição no dicionário, intersecção pode ser traduzida na "operação sobre dois ou mais conjuntos de que resulta um conjunto com todos os elementos que são comuns" ${ }^{58}$. Em razão disso, a sua representação gráfica pode se dar da seguinte forma:

Figura 1. 


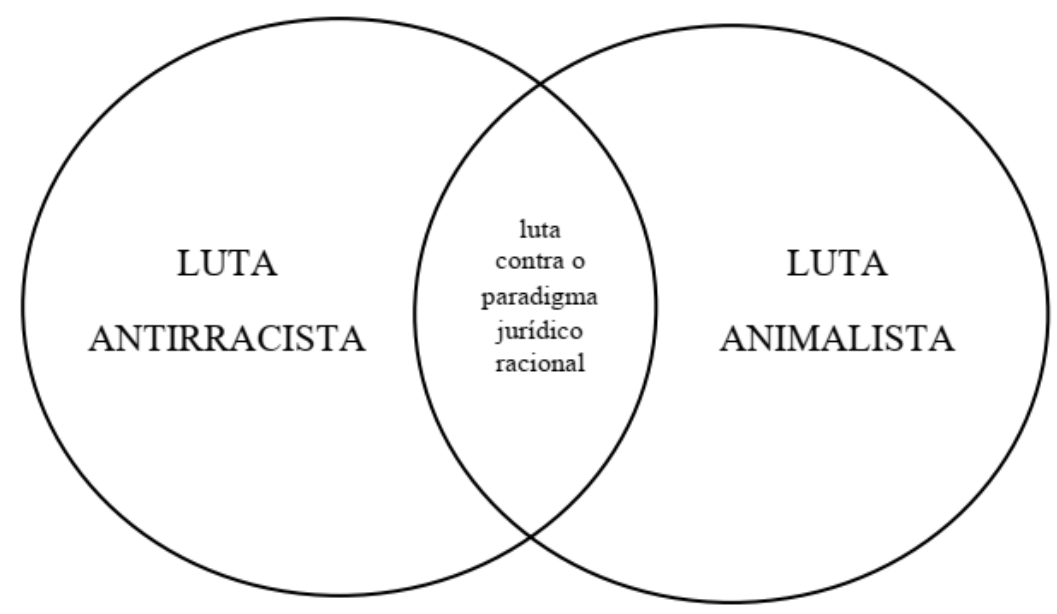

Fonte: produzido pelas Autoras.

A primeira pesquisadora que melhor trabalhou o tema, por sua vez, foi a professora Kimberlé Crenshaw, que definiu o conceito de interseccionalidade nos seguintes termos:

A interseccionalidade é uma conceituação do problema que busca capturar as consequências estruturais e dinâmicas da interação entre dois ou mais eixos da subordinação. Ela trata especificamente da forma pela qual o racismo, o patriarcalismo, a opressão de classe e outros sistemas discriminatórios criam desigualdades básicas que estruturam as possíveis relativas de mulheres, raças, etnias, classes e outras. ${ }^{59}$

Com efeito, a utilização do termo pela autora foi, inicialmente, com o propósito de compreender de que forma as opressões de gênero, raça e classe se cruzam e afetam mulheres negras. ${ }^{60}$ Para Crenshaw, não é possível esperar que mulheres negras escolham contra qual opressão lutar primeiro - racial, econômica ou de gênero.

Pelo contrário, uma vez que elas são perpassadas por todas as formas de opressão ao mesmo tempo, não há como separar qual é a causa mais importante. É preciso, assim, encontrar uma maneira - a interseccionalidade - que Ihes permita a articulação concomitante contra todas essas formas de discriminação.

Desvendando o texto de sua contemporânea, Patricia Hill Collins destaca que a advogada "está claramente defendendo a interseccionalidade como uma construção de justiça social, e não como uma teoria da verdade desvinculada das preocupações com justiça social" ${ }^{\prime \prime}$, ainda mais na medida em que tenta

(1) estabelecer relações entre identidade individual e identidade coletiva; (2) manter o foco nas estruturas sociais; (3) teorizar a partir da base (em de um modelo top-down) casos de violência contra mulheres de cor como um conjunto de experiências com conexões estruturais, políticas e representativas; (4) lembrar leitoras que o propósito dos estudos interseccionais é contribuir com iniciativas de justiça social. ${ }^{62}$

Nesse sentido, "a eficácia das ideias centrais de interseccionalidade, em situações díspares politicamente, levanta questões importantes sobre a relevância do conhecimento para a luta por liberdade e iniciativas de justiça social" ${ }^{63}$. No caso das lutas antirracista e animalista, por 
óbvio, a interseccionalidade das lutas não parte da sobreposição das suas minorias protegidas ou seja, não se trata de encontrar os pontos em comum entre seres humanos negros e negras e animais não-humanos.

A interseccionalidade que se propõe é aquela que é pautada pelo que se tem chamado de Movimento Afro Vegano ou Veganismo Interseccional. Em que pese não haja, ainda, uma articulação a nível nacional, existem já diversas páginas, em especial, nas redes sociais, que apresentam as principais diretivas das pessoas que tem se engajado nesse movimento.

No ponto, destaca-se que, em uma sociedade cada vez mais conectada globalmente, é preciso dar atenção às manifestações que vem ocorrendo através da internet, muitas vezes compreendidas como ciberativismo. Segundo Diniz e Caleiro, o ativismo digital é uma via alternativa "ao monopólio exercido pelos meios de comunicação de massa" ${ }^{64}$, uma vez que

Os ativistas encontram na web 2.0 um instrumento democrático, potencialmente expansivo e rizomático, capaz de açular debates na rede, de temas passíveis de cerceamento na mídia corporativa e de outros já abordados pelos meios de comunicação de massa tradicionais, porém, sem a rigidez de controles ou filtros na informação por estes apresentada. ${ }^{65}$

Em razão disso, em que pese a ausência de referências de cunho mais científico sobre a proposta do Movimento Afro Vegano, isso não retira a relevância das pautas trazidas, que podem ter muito a contribuir para o presente trabalho, conforme se demonstrará a seguir. Insta registrar que, em nenhum momento, ignora-se o fato de que o foco do Movimento é para pessoas negras que aderem à dieta vegana, o que não implica, necessariamente, que sejam também pessoas adeptas a toda a agenda da causa animalista.

Todavia, a ideia de interseccionalidade que é trazida auxilia para a concepção uma atuação em conjunto do movimento negro e do movimento animalista, razão pela qual vem ao encontro do proposto no presente artigo. Assim, delimitados alguns pontos iniciais, imperiosa a análise do que seria o foco do Movimento Afro Vegano e um possível conceito para a expressão "veganismo interseccional".

De acordo com o blog Vegana Gente, do autor Robson Fernando de Souza, veganismo interseccional poderia ser definido como

uma versão amadurecida de veganismo que reconhece os inquebráveis elos entre o modo de vida vegano, a luta pelos direitos dos animais não humanos e as lutas pela libertação dos seres humanos, em especial das minorias políticas (mulheres, pessoas negras, pessoas pobres, LGBTs, pessoas com deficiência e neurodiversas, imigrantes e pessoas refugiadas, minorias religiosas e irreligiosas etc.). ${ }^{66}$

Dessa forma, o autor reconhece a necessidade de se pensar a pauta dos direitos dos animais em conjunto a outras lutas sociais voltadas, em especial, para a proteção de categorias vulneráveis. Tal conceito, porém, como referido pelo próprio autor, não é um conceito fixo e imutável, estando sujeito a alterações.

Com efeito, veja-se que, apesar da contribuição, o foco ainda não é, ao menos especificamente, a conjunção específica da causa animal e racial - reconhece-se o elo, mas não se propõe uma abordagem para além dele. Nesse sentido, o Movimento Afro Vegano apresenta um recorte racial e de classe capaz de melhor abarcar essas duas demandas, na medida em que busca mostrar para pessoas negras 
as vantagens de uma alimentação baseada em plantas, sobre a saúde do povo preto, do sentimento de compaixão pela vida animal não humana e humana igualmente, do menor impacto ambiental de uma vida vegana que favorece as gerações futuras. ${ }^{67}$

A interseccionalidade, como ferramenta-chave do feminismo negro, permite que sejam superadas as categorias de raça, classe, gênero, sexualidade, nacionalidade e capacidades, "para entender as inter-relações entre ideias e processos que parecem ser isolados e dissociados" 68 . Para Angela Davis, isso significa que compreender que "há ligações entre as lutas e o racismo nos Estados Unidos e as lutas contra a repressão israelense ao povo palestino é um processo feminista" ${ }^{\prime 69}$.

Trazendo este conceito para o tema deste trabalho, compreender que as lutas do movimento negro e as lutas do movimento animal podem, juntas, colaborar uma com a outra, para fins de superação do paradigma jurídico racional que permite a objetificação de corpos negros e animais não-humanos, é também um processo feminista. Nessa perspectiva, não há necessidade de comparação nem de confronto.

Para Angela P. Harris, racismo e especismo compartilham também "a história de uma episteme em que a natureza e a cultura são violentamente separados e o sujeito moderno emerge, nostálgico acerca da ruptura"70. No ponto, logo após a era industrial, esse processo de racionalização se intensifica, de forma que "o racismo justifica e racionaliza a exploração e a degradação tanto de pessoas pobres quanto de pessoas de cor, assim como o progresso econômico justifica e racionaliza a exploração e a degradação da natureza" ${ }^{71}$.

O Direito, por sua vez, é uma das esferas que mais incorpora essa racionalidade, sob a proposta de oferecer uma decisão jurídica imparcial e desvinculada de valores morais. Desse modo, acaba por não permitir o questionamento direto de leis que porventura reproduzam o racismo, principalmente, de forma velada, bem como, incorporado de uma visão sobremaneira antropocêntrica, dificulta a releitura do enquadramento de animais não-humanos para além de seres somente sencientes.

Em razão disso, tanto a causa animal quanto a causa racial, por meio da interseccionalidade, podem adotar a luta contra o paradigma jurídico racional dominante como uma abordagem em comum. De fato, somente a superação desse paradigma racional, que legitimou por séculos a escravidão e, até hoje, permite a existência de um sistema jurídico focado na criminalização de pessoas negras, e que ainda não reconhece a possibilidade de conceder personalidade jurídica para animais não-humanos é que se poderá repensar as categorias jurídicas em que essas minorias se encontram a partir de um novo locus.

Para Collins, uma das principais contribuições do pensamento feminista negro, isto é, do pensamento de mulheres negras, é justamente o que ela chama de natureza interligada de opressões. Trata-se, em verdade, de um ponto de vista inovador, que muda o foco da investigação de uma abordagem "que tinha como objetivo explicar os elementos de raça, gênero ou opressão de classe, para outra que pretende determinar quais são os elos entre esses sistemas" ${ }^{\prime 72}$.

Afinal, faz muito mais sentido buscar os pontos em comum, a fim de que seja possível lutar contra mais de uma forma de discriminação ao mesmo tempo, do que elencar qual cenário é o mais importante. Collins destaca, porém, que é necessário pensar uma interseccionalidade capaz de avançar "em um contexto político e epistêmico da academia neoliberal" "73 em que há a valorização da "realização individual e a responsabilidade pessoal acima das ideias coletivas relativas ao bem público" ${ }^{\prime 74}$.

Veja-se que o que se propõe é justamente a adoção de uma perspectiva a partir das pessoas negras e dos animais não-humanos, em que ambos os grupos buscam ser devidamente 
reconhecidos pelo ordenamento jurídico como seres dignos de respeito e inclusão igualitária. Em outras palavras, é reconhecer o lugar de fala da luta antirracista e da luta animalista, de modo que seus ativistas possam propor categorias jurídicas que efetivamente abarquem, com a propriedade que lhes cabe, a igualdade material de grupos historicamente segregados.

Uma política emancipatória interseccional contra o racismo e o especismo, portanto, exige que a busca por mudanças jurídicas não se dê de maneira impensada e de forma a prejudicar o outro. Conforme referido anteriormente, a interseccionalidade não permite a desvalorização de qualquer das opressões com as quais se está trabalhando.

Apesar de extremamente recente, o Movimento Afrovegano é igualmente inovador, na medida em que serve como início de prova material de que é, sim, possível esse diálogo entre o movimento dos direitos dos animais e o movimento negro. No ponto, esse olhar parte justamente do movimento negro, em especial, através do olhar feminista negro, pois as mulheres negras, na qualidade de outsider within, ${ }^{75}$ podem trazer uma perspectiva totalmente inovadora da realidade social. Seu olhar de um indivíduo marginalizado, como o Outro do Outro, ${ }^{76}$ permite um olhar de fora da estrutura e, ao mesmo tempo, de dentro, que permite repensar formas de enfrentamento de injustiças sociais.

\section{Considerações Finais}

Notícias e julgamentos judiciais recentes têm demonstrado que permanece aceso um aparente embate entre as causas animalista e antirracista. O presente trabalho, porém, propôs-se justamente a aprofundar a discussão, indo além da tão temida comparação de opressões.

Nesse sentido, em um primeiro momento, a pesquisa realizada permitiu verificar que a busca da ciência por uma racionalidade estritamente objetiva foi o principal instrumento a garantir a objetificação tanto da população negra como dos animais não-humanos, que, de diferentes formas, foram tratados como mercadoria pelo poder dominante. Ainda que não seja possível equiparar - e exatamente isto que não se pretende fazer -, tanto a causa animal quanto a causa racial surgiram das consequências geradas pela objetificação do Outro dentro de um paradigma racional que tem no capitalismo o seu principal aliado.

Assim, utilizando-se do conceito de Kimberlé Crenshaw, foi possível estabelecer um ponto de interseccionalidade entre o movimento animalista e antirracista e, a partir disso, pensar em formas de emancipação conjunta para os dois lados. Por óbvio, isso implica dizer que nenhuma luta pode se sobrepor a outra, devendo, antes disso, buscarem uma releitura das categorias jurídicas que mantêm a sua subjugação e, consequentemente, um novo locus social, que priorize o lugar de fala das minorias em questão.

Com isso em mente, o presente trabalho teve acesso ao chamado "Movimento Afrovegano", que é uma iniciativa em que pessoas negras visam justamente buscar uma compreensão holística de mundo, onde seja possível lidar com as inter-relações entre duas pautas que, em um primeiro momento, parecem totalmente dissociadas. Ao buscar uma forma de alimentação que não se utiliza da exploração animal e voltada também para o bem-estar da população negra, o Movimento Afrovegano se mostra inovador, em um momento onde o Supremo Tribunal Federal colocou em pauta novamente uma questão sensível para os dois lados estudados.

De todo modo, não se desconsidera que eventuais debates entre o movimento negro e o movimento animalista possam acontecer. De fato, em havendo o aparente conflito, entende-se que, partindo do ponto de que não se tratam de causas opostas, é possível pensar em uma maneira de conciliá-las, como se faz hoje em dia no caso do aparente conflito entre normas fundamentais, em que são aplicados os princípios da razoabilidade e da proporcionalidade, por exemplo. 
O presente trabalho, porém, não pretende esgotar o assunto, senão demonstrar, a partir de uma perspectiva feminista negra, de que, apesar de eventuais divergências, a cooperação pode ser mais eficiente que a comparação tanto para a causa animal, quanto para a causa racial. Comungando-se do olhar do feminismo negro, que já parte de uma perspectiva do sujeito marginalizado pelo paradigma racional dominante, concluiu-se que a interseccionalidade da discussão apresenta um horizonte mais capaz de promover mudanças no longo prazo, assim como o Movimento Afrovegano se propõe.

\section{Notas de referência}

1. SPIEGEL, Marjorie. The Deadred Comparison: human and animal slavery. New York: Mirror Books, 1996.

2. Ibidem, p. 19.

3. DAVIS, Angela. Mulheres, raça e classe. São Paulo: Boitempo, 2016, p. 17.

4. Ibidem, p. 20.

5. PIRES, Breiller. Grêmio e Aranha, uma história de racismo perverso e continuado. Opinião, EI Pais Brasil, 17 de julho de 2017. Disponível em: https://brasil.elpais.com/brasil/2017/07/17/deportes/1500309484_868649.html. Acesso em 04 ago. 2019.

6. KO, Aph. 3 Motivos Pelos Quais Pessoas Negras Não Se Engajam No Movimento Dos Direitos Dos Animais. E Por Que Elas Deveriam. Trad. Modefica. Modefica, 24 de abril de 2016. Disponível em: https://www.modefica.com.br/movimento-negro-direitos-animais/\#.XS37UehKjcs. Acesso em 16 jul. 2019.

7. A FÚRIA vegan e o nosso direito. Afropress, 26 de outubro de 2007. Disponível em: https://web.archive.org/web/20071206083045/http://www.veddas.org.br:80/editorialafropress. htm. Acesso em 17 jul. 2019.

8. Ibidem.

9. NACONECY, Carlos. A discriminação moral contra animais: o conceito de especismo. Revista Diversitas, São Paulo, ano 4, n. 5, out./2015 a mar./2016, p. 32. Disponível em: http://diversitas.fflch.usp.br/sites/diversitas.fflch.usp.br/files/1_NACONENCY,\%20C.\%20A\%20disc rimina\%C3\%A7\%C3\%A30\%20moral\%20contra\%20os\%20animais.pdf. Acesso em 15 jul. 2019.

10. Ibidem.

11. NACONECY, Carlos. As (des)analogias entre racismo e especismo. Revista Brasileira de Direito Animal, Salvador, v. 5, n. 6, jan./jun. 2010, p. 171 . Disponível em: https://portalseer.ufba.br/index.php/RBDA/article/view/11077/8153. Acesso em 15 jul. 2019.

12. SINGER, Peter. Libertação animal. Porto Alegre: Lugano, 2004, p. 8.

13. Ibidem, p. 8 e 11.

14. Ibidem, p. 8 e 11.

15. RYDER, Richard. Animals and Human Rights. Revista Brasileira de Direito Animal, Salvador, v. 3, n. 4, jan./jun. 2008 p. 63. Disponível em: https://portalseer.ufba.br/index.php/RBDA/article/view/11077/8153. Acesso em 15 jul. 2019.

16. PAZÓ, Cristina Grobério; CARPES, Lorena Ferreira. A interferência do especismo no reconhecimento como sujeitos de direito dos animais não-humanos. Revista Internacional de Direito Ambiental e Políticas Públicas, n. 6, 2014, p. 14 . Disponível em: https://periodicos.unifap.br/index.php/planeta/article/view/1192/1113. Acesso em 04 ago. 2019. 17. SCHWARCZ, Lilia Moritz. Teorias raciais. In: SCHWARCZ, Lilia Moritz; GOMES, Flávio (orgs.). Dicionário da Escravidão e Liberdade. 1. ed. São Paulo: Companhia das Letras, 2018, p. 403-409. 
18. REGAN, Tom. Jaulas vazias: encarando o desafio dos direitos animais. Trad. Regina Rheda. Porto Alegre: Lugano, 2006, p. 78.

19. Ibidem.

20. FRANCIONE, Gary L. Introduction to Animal Rights: Your Child or the Dog? Philadelphia: Temple University Press, 2000. p. 173.

21. NACONECY, Carlos. Op. cit., 2010, p. 201.

22. Ibidem.

23. Significado de Comparar. Dicionário do Aurélio Online, 2019. Disponível em: https://dicionariodoaurelio.com/comparar. Acesso em: 16 de Jul. de 2019.

24. BRASIL. Supremo Tribunal Federal (Tribunal Pleno). Recurso Extraordinário 494601/RS. Direito constitucional. Recurso extraordinário com repercussão geral. Proteção ao meio ambiente. Liberdade religiosa. Lei 11.915/2003 do estado do rio grande do sul. Norma que dispõe sobre o sacrifício ritual em cultos e liturgias das religiões de matriz africana. Competência concorrente dos estados para legislar sobre florestas, caça, pesca, fauna, conservação da natureza, defesa do solo e dos recursos naturais, proteção do meio ambiente e controle da poluição. Sacrifício de animais de acordo com preceitos religiosos. Constitucionalidade. Recorrente: Ministério público do Estado do Rio Grande do Sul. Recorrido: Governador do Estado do Rio Grande do Sul e Assembleia Legislativa do Estado do Rio Grande do Sul. Relatora: Min. Edson Fachin, 28 de março de 2019. Disponível em: http://redir.stf.jus.br/paginadorpub/paginador.jsp?docTP=TP\&doclD=751390246. Acesso em: 11 mar. 2020.

25. RIO GRANDE DO SUL. Lei no 11.915, de 21 de maio de 2003. Institui o Código Estadual de Proteção aos Animais, no âmbito do Estado do Rio Grande do Sul. Porto Alegre: Assembleia Legislativa do Estado do Rio Grande do Sul [2003]. Disponível em: https://www.ufrgs.br/bioetica/11915an.htm. Acesso em: 11 mar. 2020.

26. SILVA, Daniel Neves. Por que não pode comer carne na Sexta-Feira Santa?. Brasil Escola. Disponível em: https://brasilescola.uol.com.br/pascoa/por-que-nao-pode-comer-carne-na-sextafeira-santa.htm. Acesso em 04 ago. 2019.

27. Ibidem.

28. KOSHER e halal: como os animais devem ser sacrificados segundo os rituais judeus e muçulmanos. BBC News Brasil, 10 de janeiro de 2019. Disponível em: https://www.bbc.com/portuguese/internacional-46786317. Acesso em 04 ago. 2019.

29. Ibidem.

30. HISTÓRIA. Comunidade Israelita do Brasil. Disponível em: http://www.conib.org.br/historia/. Acesso em 04 ago. 2019.

31. AZEVEDO, Reinaldo. O IBGE e a religião - Cristãos são 86,8\% do Brasil; católicos caem para 64,6\%; evangélicos já são 22,2\%. Blog Reinaldo Azevedo, Veja, 18 de fevereiro de 2017. Disponível em: $\quad$ https://veja.abril.com.br/blog/reinaldo/o-ibge-e-a-religiao-cristaos-sao-86-8-do-brasilcatolicos-caem-para-64-6-evangelicos-ja-sao-22-2/. Acesso em 04 ago. 2019.

32. BRASIL. Op. cit.

33. FERNANDES, Nathalia Vince Esgalha. A raiz do pensamento colonial na intolerância religiosa contra religiões de matriz africana. Revista Calundu - Gira Epistemológica, Brasília - DF, v. 1, n. 1, jan./jun. 2017, 2 p. 119.2 Disponível em: http://periodicos.unb.br/index.php/revistacalundu/article/view/7627/6295. Acesso em 04 ago. 2019.

34. MOTTA, Aydano André; JACOBS, Cláudia Silva. País registra cada vez mais agressões e quebras de terreiros. Sociedade, Super Interessante, 02 de fevereiro de 2018. Disponível em: https://super.abril.com.br/sociedade/pais-registra-cada-vez-mais-agressoes-e-quebras-deterreiro/. Acesso em 04 ago. 2019. 
35. NATALY Neri: Racismo no movimento vegano. Produção de Nataly Neri, 2019. 1 vídeo (20 minutos). Disponível em: https://www.youtube.com/watch?v=0gOXmZqo6mY\&t=178s. Acesso em 18 jul. 2019.

36. DESCARTES, René. Discurso do método. 2. ed. São Paulo: Martins Fontes, 2001.

37. BATTISTI, César Augusto. O método de análise cartesiano e o seu fundamento. Scientiae Studia, São Paulo, v. 8, n. 4, p. 571-596, dez. 2010 . Disponível em: http://www.scielo.br/scielo.php?script=sci_arttext\&pid=S1678-

31662010000400004\&Ing=en\&nrm=iso. Acesso em 18 ago. 2019.

38. ARAÚJO, Fabio Roque da Silva. A ruptura do paradigma cartesiano e alguns dos seus reflexos jurídicos. Revista CEJ, Brasília, DF, v. 13, n. 46, jul./set. 2009, p. 81. Disponível em: http://www.jf.jus.br/ojs2/index.php/revcej/article/viewFile/1100/1286. Acesso em 18 ago. 2019. 39. Ibidem.

40. SEGATO, Rita Laura. Gênero e colonialidade: em busca de chaves de leitura e de um vocabulário estratégico descolonial. E-cadernos CES [online], № 18, ano 2012. Tradução de Rose Barboza. Disponível em: http://journals.openedition.org/eces/1533. Acesso em 31 jul. 2019.

41. DESCARTES, René. Op. cit.

42. KELSEN, Hans. Teoria Pura do Direito. São Paulo: Martins Fontes, 1999, p. 52.

43. Ibidem.

44. PEREIRA, Julio Cesar R (org.). Popper: as aventuras da racionalidade. Porto Alegre: EDIPUCRS, 1995, p. 11.

45. SCHWARCZ, Lilia Moritz. Op. cit., p. 403-409.

46. SPIEGEL, Marjorie. Op. cit., p. 16.

47. CORREIA, Sandro S. A contribuição da cultura desenvolvida nos templos da religiosidade de matriz africana para um território sustentável nas cidades. In: ANAIS DO $\vee$ ENCONTRO DE ESTUDOS MULTIDISCIPLINARES EM CULTURA (ENECULT), 2009, Salvador. Anais... Salvador: Universidade Federal da Bahia, 2009.

48. CARNEIRO, Sueli. A construção do outro como não-ser como fundamento do ser. 2005. 339 p. Tese (Doutorado em Educação). Universidade de São Paulo, São Paulo, 2005, p. 97. Disponível em: https://negrasoulblog.files.wordpress.com/2016/04/a-construc3a7c3a3o-do-outro-comonc3a3o-ser-como-fundamento-do-ser-sueli-carneiro-tese1.pdf. Acesso em 12 jul. 2019.

49. MATTOS, Hebe; GRINBERG, Keila. Código Penal Escravista e Estado. In: SCHWARCZ, Lilia Moritz; GOMES, Flávio (orgs.). Dicionário da Escravidão e Liberdade. 1. ed. São Paulo: Companhia das Letras, 2018, p. 164.

50. FLAUZINA, Ana Luiza Pinheiro. Corpo negro caído no chão: o sistema penal e projeto genocida do estado penal brasileiro. 2006. 145 p. Dissertação (Mestrado em Direito). Universidade de Brasília, Brasília, DF, 2006, p. 69.

51. SANTOS, Thandara (org.). Levantamento nacional de informações penitenciárias: INFOPEN Mulheres. 2. ed. Brasília: Ministério da Justiça e Segurança Pública; Departamento Penitenciário Nacional, 2017, p. 40. Disponível em: http://depen.gov.br/DEPEN/depen/sisdepen/infopenmulheres/infopenmulheres_arte_07-03-18.pdf. Acesso em 25 jul. 2019.

52. ANISTIA INTERNACIONAL. Você matou meu filho!: homicídios cometidos pela polícia militar na cidade do Rio de Janeiro. Rio de Janeiro: Anistia Internacional, 2015. Disponível em:< https://anistia.org.br/wp-content/uploads/2015/07/Voce-matou-meu-filho_Anistia-Internacional2015.pdf>. Acesso em 15 jul. 2019.

53. ADAMS, Carol. A política sexual da carne: a revolução entre o carnivorismo e a dominância masculina. Alaúde: São Paulo, 2012.

54. "Convergent evidence indicates that non-human animals have the neuroanatomical, neurochemical, and neurophysiological substrates of conscious states along with the capacity to exhibit intentional behaviors". In: LOW, Philip. The Cambridge Declaration on Consciousness. 
Tradução

livre.

Disponível

em:

http://fcmconference.org/img/CambridgeDeclarationOnConsciousness.pdf. Acesso em 15 set. 2019.

55. BRASIL. [Constituição (1988)]. Constituição da República Federativa do Brasil de 1988. Brasília, DF: Presidência da República, [2016]. Disponível em: http://www.planalto.gov.br/ccivil_03/Constituicao/Constituiçao.htm. Acesso em: 11 mar. 2020. 56. ATAIDE JUNIOR, Vicente de Paula. Introdução ao direito animal brasileiro. Revista Brasileira de Direito Animal, Salvador, v. 13, n. 13, p. 48-76, set./dez. 2018, p. 50. Disponível em: https://portalseer.ufba.br/index.php/RBDA/article/view/28768/17032. Acesso em 15 set. 2019.

57. ADAMS, Carol. Op. cit., p. 25.

58. Significado de Interseção. Dicionário do Aurélio Online, 2019. Disponível em: https://dicionariodoaurelio.com/intersecao. Acesso em 05 ago. 2019.

59. CRENSHAW, KIMBERLÉ. Documento para o encontro de especialistas em aspectos da discriminação racial relativos ao gênero. Revista Estudos Feministas, Florianópolis, v. 10, n. 1, jan. 2002, $177 . \quad$ p. Disponível em: http://www.scielo.br/scielo.php?script=sci_arttext\&pid=S0104-

026X2002000100011\&lng=en\&nrm=iso. Acesso em 17 jul. 2019.

60. O feminismo universal, de fato, tem uma tendência a presumir "erroneamente que as causas das mulheres podem ser articuladas de modo isolado das questões associadas aos movimentos negro e trabalhador". Desse modo, "suas teorias e práticas frequentemente insinuaram que a contestação mais pura e direta ao sexismo é aquela desprovida de elementos ligados à opressão racial e econômica - como se existisse um fenômeno como a feminilidade abstrata que sofre o sexismo de maneira abstrata e que luta contra ele em um contexto histórico abstrato". In: DAVIS, Angela. Mulheres, cultura e política. 1. ed. São Paulo: Boitempo, 2017, p. 26.

61. COLLINS, Patricia Hill. Se perdeu na tradução? Feminismo negro, interseccionalidade e política emancipatória. Parágrafo, São Paulo, jan./jun. 2017, v.5, n. 1, 2017, p. 12. Disponível em: http://revistaseletronicas.fiamfaam.br/index.php/recicofi/article/view/559/506. Acesso em 08 set. 2019.

62. Ibidem.

63. Ibidem, p. 7.

64. DINIZ, Gabriela Faleiro; CALEIRO, Maurício. Web 2.0 e Ciberativismo: O poder das redes na difusão de Movimentos Sociais. Revista Científica do Departamento de Comunicação Social da Universidade Federal do Maranhão, São Luís, ano 19, n. 8, jan./jun. 2011, p. 42. Disponível em: http://www.cambiassu.ufma.br/cambi2011.1/iara.pdf. Acesso em 05 ago. 2019.

65. Ibidem.

66. SOUZA, Robson Fernando. Introdução ao veganismo interseccional: respondendo a 10 perguntas sobre essa forma amadurecida do veganismo. Vegana Gente, 07 de maio de 2017. Disponível em: http://veganagente.com.br/introducao-veganismo-interseccional/. Acesso em 05 ago. 2019.

67. EM DIVERSOS espaços e movimentos sociais existe racismo. [...]. Rio de Janeiro, 24 out. 2018. Instagram: @movimentoafrovegano. Disponível em: https://www.instagram.com/p/BpVqi9pBdQ/. Acesso em 04 ago. 2019.

68. DAVIS, Angela. A liberdade é uma luta constante. São Paulo: Boitempo, 2018, p. 21.

69. Ibidem.

70. HARRIS, Angela P. As pessoas de cor deveriam apoiar os direitos dos animais?. Revista Brasileira de Direito dos Animais, Salvador, ano 5, v. 7, jul./dez. 2010, p. 59. Disponível em: https://rigs.ufba.br/index.php/RBDA/article/viewFile/11040/7960. Acesso em 15 jul. 2019. 
71. COLLIN, Robert W.; COLLIN, Robin Morris. Sustainability and Environmental Justice: Is the Future Clean and Black? Environmental Law Reporter, n. 8, ago. 2001. Disponível em: https://elr.info/news-analysis/31/10968/sustainability-and-environmental-justice-future-cleanand-black. Acesso em 17 jul. 2019.

72. COLLINS, Patricia Hill. Aprendendo com a outsider within: a significação sociológica do pensamento feminista negro. Revista Sociedade e Estado, v. 31, n. 1, p. 99-127, jan./abr. 2016, p. 108. Disponível em: http://www.scielo.br/pdf/se/v31n1/0102-6992-se-31-01-00099.pdf. Acesso em 09 set. 2019.

73. COLLINS, Patricia Hill. Op. cit., 2017, p. 15.

74. Ibidem.

75. "Por um lado, essa relação de insider tem sido satisfatória para todos os envolvidos. Nas biografias dos brancos ricos, é frequente o relato de seu amor por suas "mães" negras, enquanto os relatos das trabalhadoras domésticas negras ressaltam a percepção de autoafirmação vivenciada pelas trabalhadoras ao verem o poder branco sendo desmistificado - saberem que não era o intelecto, o talento ou a humanidade de seus empregadores que justificava o seu status superior, mas o racismo. No entanto, por outro lado, essas mesmas mulheres negras sabiam que elas jamais pertenceriam a suas "famílias" brancas. Apesar de seu envolvimento, permaneciam como outsiders". In: COLLINS, Patricia Hill. Aprendendo com a outsider within: a significação sociológica do pensamento feminista negro. Revista Sociedade e Estado, v. 31, n. 1, p. 99-127, jan./abr. 2016, p. 99-100. Disponível em: http://www.scielo.br/pdf/se/v31n1/0102-6992-se-3101-00099.pdf. Acesso em 09 set. 2019.

76. KILOMBA, Grada. A máscara. Tradução de Jessica Oliveira de Jesus. Cadernos de literatura em tradução, n. 16, ano 2016, p. 171-180. Disponível em: http://www.revistas.usp.br/clt/article/view/115286. Acesso em 08 set. 2019. 